\title{
Bone mass in nodal primary generalised osteoarthrosis
}

\author{
D. M. REID, N. S. J. KENNEDY, M. A. SMITH, P. TOTHILL, AND G. NUKI \\ From the Rheumatic Diseases Unit, Northern General Hospital, Department of Medicine, Western General \\ Hospital and Departments of Medical Physics and Medical Engineering, Western General Hospital and Royal \\ Infirmary of Edinburgh, University of Edinburgh
}

SUMMARY Previous studies of patients with primary osteoarthrosis of the hip have suggested an increase in bone mass compared with control populations. Nodal primary generalised osteoarthrosis is known to have a strong familial tendency. To test the hypothesis that this tendency might also lead to increased bone mass, total body calcium has been measured by in-vivo neutron activation analysis and cortical area calculated from measurements of metacarpal indices in 15 female patients with primary generalised osteoarthrosis. The results have been compared with those from 12 healthy controls matched for age, menopausal status, and skeletal size. No significant differences were noted in the total body calcium or cortical area measurements between the 2 groups either before or after correction for skeletal size and menopausal status. No relationship was found between the grade of radiological osteoarthrosis in the hand and either bone mass parameter. Bone mass would not appear to be an important factor in the aetiopathogenesis of nodal primary generalised osteoarthrosis.

Osteoarthrosis $(\mathrm{OA})$ is not a single disease but rather a pattern of biomechanical failure of joints ${ }^{1}$ which may be secondary to a variety of disorders of bone or articular cartilage. Although most theories of the pathogenesis of OA are based on primary alterations in the articular cartilage, ${ }^{2}$ Radin et al. ${ }^{34}$ have suggested that the progressive wear of fibrillated articular cartilage seen in 'primary' $O A$ results from stiffening of the subchondral bone. Clinical support for such a hypothesis comes from the observation that pathological changes of $\mathrm{OA}$ are unusual in femoral heads removed from patients with fractured necks of femur ${ }^{5}$ and that bone mass appears to be increased in patients with primary OA of the hip when assessed by measurements of metacarpal indices ${ }^{6}$ or photon absorptiometry.

To examine this hypothesis further we have assessed bone mass in female patients with nodal primary generalised osteoarthrosis by measuring total body calcium and metacarpal indices and comparing the results with controls matched for age, skeletal size, and menopausal status.

\section{Patients and methods}

Fifteen female patients with nodal primary Accepted for publication 23 February 1983.

Correspondence to Professor G. Nuki, Rheumatic Diseases Unit, Northern General Hospital, Ferry Road, Edinburgh EH5 2DQ. generalised osteoarthrosis (PGOA) fulfilling the criteria defined by Kellgren and Moore ${ }^{8}$ and 12 asymptomatic healthy women matched for age, skeletal size, and menopausal status have been studied. Serum calcium, phosphate, alkaline phosphatase, and albumin were measured in all subjects by standard methods, and persons with abnormalities of calcium metabolism or medical conditions known to be associated with secondary osteoporosis were excluded.

Total body calcium (TBCa) was measured by invivo neutron activation analysis. Patients were irradiated for 20 seconds from front and rear, while standing in a rigid polyethylene activation enclosure, by means of neutrons from the Edinburgh Medical Research Council Cyclotron. The patients were then transferred to a shadow-shield whole-body counter, where the gamma radiation from calcium ${ }^{49} \mathrm{Ca}$ induced from stable ${ }^{48} \mathrm{Ca}$ by neutron capture, was measured for 20 minutes. The patient's TBCa in grams was calculated by comparison with the energy spectrum from an activated anthropomorphic phantom of human dimensions containing a known quantity of calcium. Repeated measurements of the phantom gave a long term precision of $1.8 \%$ for a radiation dose of $13 \mathrm{mSv}(1 \cdot 3 \mathrm{rem}) .{ }^{9}$ The mean TBCa \pm 1 SD in the control population was $842 \cdot 0 \pm 142 \cdot 7 \mathrm{~g}$. Individual results were expressed both in grams and 
as a percentage of the expected normal value for the patient's skeletal size (arm span) and menopausal status. After correction for arm span and menopausal status the spread in the normal controls expressed as the coefficient of variation was reduced to $6 \cdot 3 \%$.

Metacarpal indices were measured by a variation of the technique described by Dequeker. ${ }^{10} \mathrm{~A}$ single posteroanterior radiograph of the hands was taken at a uniform 1 metre tube-to-film distance using nonscreen film. Morphometric measurements were performed at the right $2 \mathrm{nd}$, 3rd, and 4th metacarpals. The length of each metacarpal was determined with a millimetre rule, and the external diameter (D) and the internal diameter (d) of the midshaft of the cortext were measured to the nearest $0.1 \mathrm{~mm}$ by means of a needle-tipped direct reading Vernier caliper. The cross-sectional cortical area was then calculated from the formula $\pi / 4\left(D^{2}-d^{2}\right)$, but omitting $\pi / 4$ by convention. The final figure was expressed as a mean of the 3 metacarpals. The precision of the technique, evaluated from 2 radiographs take at daily intervals in 10 young normal controls, was $2.0 \%$. The mean cortical area in the control population was $46.3 \mathrm{~mm}^{2}$, with a range from $37 \cdot 5$ to $52 \cdot 9 \mathrm{~mm}^{2}$.

The severity of radiographic osteoarthritic changes at the distal and proximal interphalangeal joints of each digit and at the carpometacarpal joint of the thumb was graded from 0 to 4 according to the criteria of the Atlas of Standard Radiographs. ${ }^{11}$ A composite score was derived from the sum of the changes in each of the above joints giving a possible score of $0-80$ considering both hands. All patients gave informed consent, and approval was obtained from local and national ethical committees.

\section{Results}

Details of age, menopausal status, span, height, and osteoarthrosis score for patients and controls are shown in Table 1 . The results of TBCa and cortical

Table 1 Mean age, menopausal status, span, height and osteoarthrosis score in patients with PGOA and controls; range given in parentheses

\begin{tabular}{lll}
\hline & $\begin{array}{l}\text { PGOA } \\
n=15\end{array}$ & $\begin{array}{l}\text { Controls } \\
n=12\end{array}$ \\
\hline Age (years) & $58 \cdot 5$ & $55 \cdot 5$ \\
& $(47-68)$ & $(46-65)$ \\
Years after menopause & $8 \cdot 5$ & $6 \cdot 9$ \\
& $(0-20)$ & $(0-22)$ \\
Arm span (cm) & $166 \cdot 2$ & $163 \cdot 1$ \\
Height (cm) & $(155-183)$ & $(150-175)$ \\
& $162 \cdot 2$ & $159 \cdot 8$ \\
Osteoarthrosis score & $(156 \cdot 5-170)$ & $(151-173)$ \\
& 36 & 3 \\
& $(11-64)$ & $(0-9)$ \\
\hline
\end{tabular}

Table 2 TBCa expressed in grams and as a percentage of normal and cortical area in PGOA patients and controls. Mean values $\pm S D$ with the range given in parentheses

\begin{tabular}{|c|c|c|}
\hline & $\begin{array}{l}P G O A \\
n=15\end{array}$ & $\begin{array}{l}\text { Controls } \\
n=12\end{array}$ \\
\hline TBCa in grams & $\begin{array}{l}830 \cdot 6 \pm 129 \cdot 0 \\
(590 \cdot 2-1053 \cdot 7)\end{array}$ & $\begin{array}{l}842 \pm 142 \cdot 7 \\
(596 \cdot 0-1036 \cdot 1)\end{array}$ \\
\hline TBCa-\% or normal & $\begin{array}{l}99 \cdot 5 \pm 11 \cdot 5 \\
(83 \cdot 0-120 \cdot 1)\end{array}$ & $\begin{array}{l}100 \pm 6 \cdot 31 \\
(88 \cdot 7-110 \cdot 4)\end{array}$ \\
\hline Cortical area in $\mathrm{mm}^{2}$ & $\begin{array}{l}47 \cdot 0 \pm 6 \cdot 4 \\
(36 \cdot 1-56 \cdot 0)\end{array}$ & $\begin{array}{l}46 \cdot 3 \pm 5 \cdot 2 \\
(37 \cdot 5-52 \cdot 9)\end{array}$ \\
\hline
\end{tabular}

area in the 2 groups are shown in Table 2 . The mean TBCa in control and PGOA groups showed almost identical values, both when expressed in grams and when expressed as a percentage of the expected normal values for the patient's skeletal size and menopausal status. Mean cortical area measurements in the 2 groups again showed no significant difference.

Total body calcium was highly significantly correlated with cortical area $(r=0 \cdot 722, p<0 \cdot 001)$. TBCa and cortical area were not correlated with the osteoarthrosis score (TBCa: $r=-0 \cdot 289$, cortical area: $r=$ $-0 \cdot 173)$. There was no different in any of the indices of bone mass between patients who had or had not received nonsteroidal anti-inflammatory drugs.

\section{Discussion}

These studies suggest that there are no significant differences in total bone mass (measured by TBCa) or local bone mass (measured by cortical area) in patients with PGOA compared with matched controls. Statistical analysis of the data shows that mean differences in TBCa normalised for skeletal size and menopausal status $\$ 7 \cdot 2 \%$ and cortical area $\$ 9.9 \%$ would have been significant at the $95 \%$ level in groups of this size.

Previous studies have only measured bone mass in patients with primary osteoarthrosis of the hip. Foss and Byers $^{6}$ first suggested that bone density measured by metacarpal indices was increased in patients with primary OA of the hip when compared with age matched normal subjects, but data on the skeletal size and extent of generalised osteoarthrosis in the patient group were not included. Roh et al. ${ }^{12}$ found an increase in periosteal diameter (external cortical diameter) and cortical area in primary OA of the hip compared with an age matched normal range, but the differences in females may well have been attributable to increased skeletal size. More recent studies have failed to confirm such increases in bone density using measurements of cortical area and cortical thickness ${ }^{13}$ or cortical area related to crosssectional area. ${ }^{14}$ 
Photon absorptiometric methods have been used to estimate metacarpal ${ }^{7}$ and radial bone mineral content $^{7315}$ in patients with primary OA of the hip. The results have been conflicting: one study appeared to show an increase in bone mineral content of $13 \%$ at cortical and $23 \%$ at trabecular sites, ${ }^{7}$ one showed an increase at a trabecular site alone ${ }^{15}$ and one showed no increase at either site. ${ }^{13}$

There are several possible explanations for the differences shown in these studies. The use of a stick as support might cause an increase in local bone mass, and this was eliminated in only 2 of the studies. ${ }^{75}$ More important, patients and study groups have not been closely matched for skeletal size in any of the studies where increased bone mineral has been shown. In 2 of them the osteoarthrotic groups were indeed taller than the controls. ${ }^{72}$

No previous studies have corrected for menopausal status. As it is recognised that bone loss in females occurs at a rate of $1.1 \%{ }^{16}$ to $1.5 \%$ per annum after the menopause and at a much slower rate before $(0 \cdot 37 \%),{ }^{16}$ the small changes in the bone mineral content of the skeleton shown in some of the above studies may simply be related to different menopausal status.

Our failure to show increased total skeletal bone mass in patients with PGOA makes it very unlikely that bone mineral content is important in the aetiopathogenesis of this genetically determined condition. Nevertheless, these findings do not rule out the possibility of local increases in bone density in areas adjacent to affected joints, or very small increases in total bone mass.

This work was supported by grants from the Scottish Hospital Endowment Research Trust and the Arthritis and Rheumatism Council. We are indebted to the Medical Research Council for use of the cyclotron at the Western General Hospital, Mrs Joan Gibb for radiographic assistance, and Mrs Elizabeth Law for help with the total body calcium measurements.

\section{References}

1 Sokoloff L. The pathology of osteoarthrosis and the role of ageing. In: Nuki G, ed. The aetiopathogenesis of osteoarthrosis. Tunbridge Wells: Pitman Medical, 1980: 1-15.

2 Howell D S, Sapolsky A I, Pita J C, Woessner J F. The pathogenesis of osteoarthritis. Semin Arthritis Rheum 1976; 4: 365-83.

3 Radin E L, Ehrlich M M, Weiss C A, Parker G H. Osteoarthrosis as a state of altered physiology. In: Buchanan W W, Carson Dick $\mathrm{W}$, eds. Recent advances in rheumatology. London: ChurchillLivingston: 1976: 1-18.

4 Radin E L, Paul I L, Rose R M. Osteoarthrosis as a final common pathway. In: Nuki G, ed. The aetiopathogenesis of osteoarthrosis. Tunbridge Wells: Pitman Medical, 1980: 84-9.

5 Byers P D, Contepomi C A, Farkas T A. A post mortem study of the hip joint. Ann Rheum Dis 1970; 29: 15-31.

6 Foss M V L, Byers P D. Bone density, osteoarthrosis of the hip, and fracture of the upper end of the femur. Ann Rheum Dis 1972; 31: 259-64.

7 Roh Y S, Dequeker J, Mulier J C. Bone mass in osteoarthrosis measured in vivo by photon absorptiometry. J Bone Joint Surg 1974; 56A: 587-91.

8 Kellgren J H, Moore R. Generalised osteoarthritis and Heberden's nodes. Br Med J 1952; i: 181-7.

9 Kennedy N S J, Eastell R, Ferrington C M, Simpson J D, Smith $M$ A, Tothill P. Total body neutron activation analysis of calcium: calibration and normalisation. Phys Med Biol 1982; 27: 697-707.

10 Dequeker J. Quantitative radiology: radiogrammetry of cortical bone. Br J Radiol 1976; 49: 912-20.

11 Kellgren J H, Jeffrey M R, Ball J. The epidemiology of chronic rheumatism. Atlas of standard radiographs of arthritis. Oxford: Blackwell, 1963: 2.

12 Roh Y S, Dequeker J, Mulier J C. Cortical bone remodelling and bone mass in primary osteroarthrosis of the hip. Invest Radiol 1973; 8: 251-4.

13 Alhava E M, Kettunen $K$, Karjalainen P. Bone mineral in patients with osteoarthrosis of the hip. Acta Orthop Scand 1975; 46: 709-15.

14 Solomon L, Schnitzler C M, Browett J P. Osteoarthritis of the hip: the patient behind the disease. Ann Rheum Dis 1982; 41: 118-25.

15 Carlsson A, Nilsson B E, Westlin N E. Bone mass in primary coxarthrosis. Acta Orthop Scand 1979; 50: 187-9.

16 Cohn S H, Vaswani A, Zanzi I, Aloia J F, Roginsky M S, Ellis $\mathrm{K} \mathbf{J}$. Changes in body chemical composition with age measured by total body neutron activation analysis. Metabolism 1976; 25: 85-95. 